\title{
Solar Spectral and Module Temperature Influence on the Outdoor Performance of Thin Film PV Modules Deployed on a Sunny Inland Site
}

\author{
G. Nofuentes, ${ }^{1}$ J. de la Casa, ${ }^{1}$ M. Torres-Ramírez, ${ }^{1}$ and M. Alonso-Abella ${ }^{2}$ \\ ${ }^{1}$ Grupo de Investigación y Desarrollo de Energía Solar, IDEA, Escuela Politécnica Superior, University of Jaén, \\ Campus de Las Lagunillas, s/n, 23071 Jaén, Spain \\ ${ }^{2}$ CIEMAT/DER, Avenida Complutense 22, 28040 Madrid, Spain
}

Correspondence should be addressed to G. Nofuentes; gnofuen@ujaen.es

Received 25 January 2013; Revised 29 September 2013; Accepted 30 September 2013

Academic Editor: Keith Emery

Copyright (c) 2013 G. Nofuentes et al. This is an open access article distributed under the Creative Commons Attribution License, which permits unrestricted use, distribution, and reproduction in any medium, provided the original work is properly cited.

\begin{abstract}
This work aims at analysing the influence of both module temperature and solar spectrum distribution on the outdoor performance of the following thin film technologies: hydrogenated amorphous silicon (a-Si:H), cadmium telluride (CdTe), copper indium gallium selenide sulfide (CIGS), and hydrogenated amorphous silicon/hydrogenated microcrystalline silicon hetero-junction (a$\mathrm{Si}: \mathrm{H} / \mu \mathrm{c}-\mathrm{Si}: \mathrm{H})$. A 12-month experimental campaign carried out in a sunny inland site in which a module of each one of these technologies was tested and measured outdoors has provided the necessary empirical data. Results show that module temperature exerts a limited influence on the performance of the tested a-Si:H, CdTe, and a-Si:H/ $\mu c-S i: H$ modules. In contrast, the outdoor behaviour of the CIGS module is the most affected by its temperature. Blue-rich spectra enhance the outdoor behaviour of the a-Si:H and a-Si:H/ $\mu \mathrm{c}-\mathrm{Si}: \mathrm{H}$ modules while it is the other way round for the CIGS module. However, the CdTe specimen shows little sensitivity to the solar spectrum distribution. Anyway, spectral effects are scarcely relevant on an annual basis, ranging from gains for the CIGS module (1.5\%) to losses for the a-Si:H module (1.0\%). However, the seasonal impact of the spectrum shape is more noticeable in these two materials; indeed, spectral issues may cause performance gains or losses of up to some $4 \%$ when winter and summer periods are considered.
\end{abstract}

\section{Introduction}

Doubtless, crystalline silicon (c-Si) is today's photovoltaic (PV) dominating technology. Although it will likely preserve its prevalence in the near and midterm, PV designers and installers are increasingly interested in thin film technologies, still a small but noticeable share of the market. If all announced expansion plans had been completed in due time, thin film production capacity could already have reached around $17 \mathrm{GW}-19 \%$ of the envisaged market-in 2012 [1]. Some estimates forecast thin film production capacity will rise up to $27 \mathrm{GW}-$ or $24 \%$ of the reported future PV marketin 2015 [2]. In this sense, recent widely marketed modules using materials such as hydrogenated amorphous silicon (a$\mathrm{Si}: \mathrm{H})$, cadmium telluride (CdTe), copper indium gallium selenide sulfide (CIGS), and hydrogenated amorphous silicon/hydrogenated microcrystalline silicon heterojunction
(a-Si:H/ $\mu \mathrm{c}-\mathrm{Si}: \mathrm{H}$ ) will certainly play a crucial role in $\mathrm{PV}$ system engineering over the next years due to their ceaseless declining cost and improved outdoor performance [1-3].

The estimation of the PV electricity yield from the climate conditions of a given site is essential in PV engineering. Hence, understanding the outdoor electrical behaviour of PV modules is a key issue for this electricity yield estimation. A wide variety of numerical, algebraic, and empirical methods referenced in the literature [4-12] have succeeded in estimating quite accurately the c-Si PV module outdoor performance. These methods basically state the relationship between the outdoor performance of these devices and two environmental factors: incident irradiance $\left(G\right.$, in $\left.\mathrm{W} \cdot \mathrm{m}^{-2}\right)$ and module temperature $\left(T_{\bmod }\right.$, in $\left.{ }^{\circ} \mathrm{C}\right)$.

However, this outdoor behaviour is not understood to such a large extent for thin film technologies [13, 14]. 
In fact, the peculiarities of their spectral responses make these technologies more sensitive to the spectral distribution of the irradiance than those based on $\mathrm{c}$-Si. Therefore, the spectrum shape must be taken into account when modeling the power output of a thin film PV module, in addition to $G$ and $T_{\text {mod }}$. Some efforts approaching this issue are worthy mention, just to give some instances. Thus, in spite of being quite accurate, the Martín and Ruiz model [15], based on equations that derive the effective responsivity of the modules from the optical air mass and the clearness index, has been solely proposed for c-Si and a-Si:H. Also, some "one-of-akind" complex models addressed to modelling the efficiency of a specific CIGS module have been proposed. This sort of complex models usually involve the clearness index, the optical air mass, and some empirical coefficients [16, 17], which cannot be conclusive for thin film technology, in general.

An interesting, well-proven, and useful method to predict the electricity yield for a given site has been reported for PV grid-connected systems (PVGCS) that use c-Si, a$\mathrm{Si}: \mathrm{H}, \mathrm{a}-\mathrm{Si}: \mathrm{H} / \mu \mathrm{c}-\mathrm{Si}: \mathrm{H}$, and a-Si/a-SiGe/a-SiGe technologies in Kusatsu city (Japan, latitude $35^{\circ} \mathrm{N}$, longitude $136^{\circ} \mathrm{E}$ ) [18-20]. To summarise, this method is mainly based on (a) obtaining a contour graph for each technology in which the module performance ratio $(\mathrm{PR})$ is depicted versus a spectral index termed average photon energy (APE, in $\mathrm{eV}$, to be stated below) and $T_{\text {mod }}$, and (b) producing contour graphs of the collected incident irradiation versus APE and the ambient temperature $\left(T_{\mathrm{amb}}\right.$, in $\left.{ }^{\circ} \mathrm{C}\right)$ of the site, which leads to a suitable characterisation of the specific site from a spectral point of view. Since $T_{\text {mod }}$ may be derived from $T_{\mathrm{amb}}$ and some other environmental factors such as wind speed, a suitable combination of the diagrams obtained in (a) and (b) is the key to achieve a good estimation of the energy yield of the above PV technologies. It should be understood that values of APE depend on the measurement wavelength interval of the spectrum. Thus, in the above works, a wavelength interval ranging from 350 to $1050 \mathrm{~nm}$ was considered, so that APE of the AM $1.5 \mathrm{G}$ spectrum equals $1.88 \mathrm{eV}$. Anyway, this issue will be dealt with more deeply in this paper.

Nevertheless, the method described above still requires a lot of research aimed at improving the understanding of the behaviour of thin film materials under natural sunlight. Thus, although CIGS and CdTe are second and third, respectively, regarding projected thin film production capacity-a-Si:H heads this rank [2] - no contour graphs depicting PR versus APE and $T_{\text {mod }}$ for these important technologies have been produced so far. Further, these contour graphs have not been obtained for sites with inland climates, in which levels of water vapour are lower-a fact that leads to shift the solar spectrum to the red-than those of sites which have a maritime climate, in which "blue rich" solar spectra prevail. More specifically, the solar spectral influence on PV materials performance has been explored for values of APE ranging from 1.85 to $2.03 \mathrm{eV}$. Therefore, the influence exerted by a "red rich" dominating spectrum on thin film technologies still remains to be suitably ascertained; that is, the impact of solar spectra with APE lower than $1.85 \mathrm{eV}$ on such technologies has not been analysed yet. Last, but not least, the works described in the previous paragraph are supported on experimental data which were drawn from the operation monitoring of several PVGCS, whose PV fields had not been calibrated at standard test conditions (STC). This experimental setup introduces some sources of uncertainty, in principle. Thus, the values for the peak power of these PV fields used in PR calculations and its further analysis have been taken from the module manufacturers' data sheets, which probably differ from the real calibrated peak power values. Further, uncertainty is also introduced in the maximum power point tracking of the PV fields; these errors should not be underestimated as most reported systems date their start of operation back to a time interval between 1998 and 2004. Existing inverters by then did not show such low values for error in maximum power point tracking as state-of-the-art inverters do nowadays. Besides, these works have not taken into account the impact on PR of the angle of incidence (AOI, in ${ }^{\circ}$ ) combined with dirt. Seasonal annealing experienced by the a-Si:H material has not been properly addressed, either.

This work aims at achieving a wider knowledge of the influence of module temperature and solar spectrum distribution on the outdoor performance of thin film PV materials, following the approach described above. Also, this work attempts to amend the shortcomings identified in the previous paragraph as much as possible. Thus, four thin film PV modules-a sample for each one of four considered technologies (a-Si:H, CIGS, CdTe, and a-Si:H/ $\mu \mathrm{c}-\mathrm{Si}: \mathrm{H}$ )—were installed outdoors in the city of Jaén (Spain, latitude $37^{\circ} \mathrm{N}$, longitude $3^{\circ} \mathrm{W}$, with a Mediterranean-Continental climate). This city is spectrally characterised by enhanced levels of long wavelengths - when compared to maritime and humid sites-due to its sunny inland and dry climate. Thus, the four selected PV specimens underwent an initial calibration in STC prior to be deployed outdoors and another one after their exposure, to check their stability over time. A 12-month experimental campaign was carried out basically intended to scan current $(I$, in $\mathrm{A})$ voltage $(V$, in $V)$ curves of these specimens together with some other environmental parameters at which these curves were scanned. For each one of the tested PV modules, a contour graph was obtained in which their outdoor performance is depicted versus APE and $T$ mod, following the approach previously described [18, 21]. PR over the experimental campaign was calculated for each tested PV module. Then, the impact of some phenomena that influence the performance of each considered PV technology over the 12-month test and measurement period-including module temperature and spectral effects-is quantified. Last, some important conclusions regarding the impact of the spectral irradiance distribution and $T_{\bmod }$ on the outdoor behaviour of the tested thin film PV modules are derived from the analysis of both the contour graphs and the quantified effects of these two influencing factors.

\section{Materials and Methods}

This section deals with a short tutorial focused on APE, introduced as a meaningful and convenient spectral index together with a description of the experimental setup from 
TABLE 1: Module maximum power in STC (W) of the four thin film PV modules under test as provided by the manufacturer and by both the initial and final outdoor calibration.

\begin{tabular}{lccc}
\hline Module technology & Manufacturer data sheet & Initial calibration (October 2011) & Final calibration (November 2012) \\
\hline a-Si: $\mathrm{H}$ & $60-5 /+10 \%$ & $57.4 \pm 4 \%$ & $56.2 \pm 4 \%$ \\
$\mathrm{CIGS}$ & $120 \pm 10 \%$ & $119.1 \pm 4 \%$ & $121.2 \pm 4 \%$ \\
$\mathrm{CdTe}$ & $70 \pm 5 \%$ & $67.2 \pm 4 \%$ & $66.5 \pm 4 \%$ \\
$\mathrm{a}-\mathrm{Si}: \mathrm{H} / \mu \mathrm{c}-\mathrm{Si}: \mathrm{H}$ & $121-5 /+10 \%$ & $109.4 \pm 4 \%$ & $107.6 \pm 4 \%$ \\
\hline
\end{tabular}

which the results to be presented here were obtained. The methodology followed to achieve the targets detailed in the previous section is also described.

2.1. The Average Photon Energy. A suitable characterisation of different spectra is a crucial requirement to assess how the solar spectral variations influence the performance of thin film PV materials. Thus, some atmospheric parameters such as the clearness index and the optical air mass condense important information on the solar spectrum distribution $[15,17]$. Nevertheless, in principle, a spectral distribution should be characterized by means of a single parameter, which could lend itself to be used just as the above environmental factors $G$ and $T_{\bmod }$. Bearing this in mind, the data recorded using a spectroradiometer are not especially adequate to achieve this characterisation, since these data consist of a more or less large set of points within a given wavelength interval, depending on the spectral range and the resolution of the used instrument. In this sense, APE has been proposed as a single index that characterizes the shape of the incident irradiance spectrum $[18,21,22]$ and, consequently, characterises its "colour." Thus, high values of APE imply that the solar spectrum is shifted towards the blue, as depicted in Figure 1. This index is calculated by dividing the integrated incident irradiance by the integrated photon flux density:

$$
\mathrm{APE}=\frac{\int_{a}^{b} G(\lambda) d \lambda}{\int_{a}^{b} \phi(\lambda) d \lambda},
$$

where $G(\lambda)\left[\mathrm{W} \cdot \mathrm{m}^{-2} \cdot \mathrm{nm}^{-1}\right]$ is the incident spectral irradiance, $\Phi(\lambda)\left[\mathrm{m}^{-2} \cdot \mathrm{nm}^{-1} \cdot \mathrm{s}^{-1}\right]$ is the incident spectral photon flux density, and $a[\mathrm{~nm}]$ and $b[\mathrm{~nm}]$ are the lower and upper wavelength limits, respectively, of the interval of the spectrum to be considered. The measurement range of the spectroradiometer usually determines the values for $a$ and $b$.

It stems from (1) that APE is an index that does not depend on the specific PV material under analysis. Besides, its uniqueness for the spectra measured in a particular site and climate has been raised [23]. Thus, APE is a meaningful and convenient index to determine the impact of the solar spectrum on PV devices outdoor behaviour [14, 24, 25]. Last, (1) shows that, given a specific solar spectral distribution, the value for APE highly depends on the lower and upper wavelength limits $-a$ and $b$, respectively - used for its calculation. Thus, APE for the AM $1.5 \mathrm{G}$ reference spectrum is equal to $1.88 \mathrm{eV}$ if the wavelength range $350-1050 \mathrm{~nm}$ is considered while this value lowers down to $1.59 \mathrm{eV}$ for the range $350-$ $1700 \mathrm{~nm}[18]$.

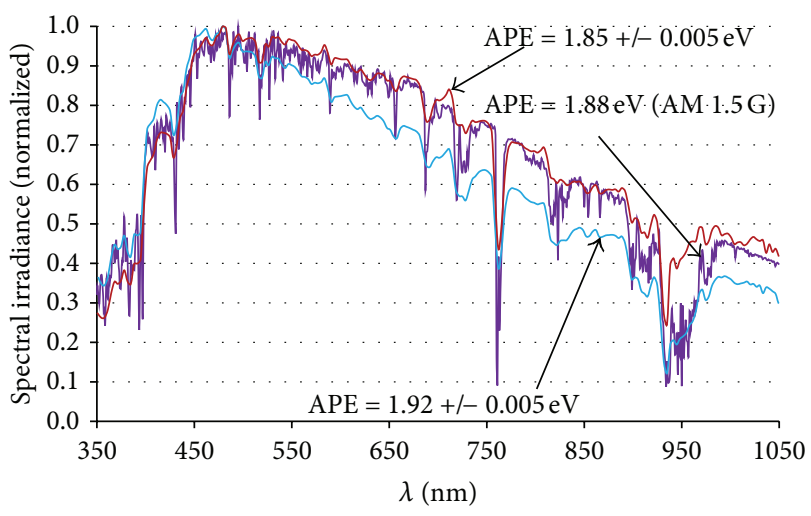

FIGURE 1: Incident spectral irradiance distributions normalized to their maxima. Redder spectra imply lower values of APE. Data corresponding to the reference AM $1.5 \mathrm{G}$ spectrum have been obtained from the IEC 60904-3 standard.

2.2. Experimental Setup. A PV module of each considered technology (a-Si:H, CIGS, CdTe, and a-Si:H/ $\mu \mathrm{c}-\mathrm{Si}: \mathrm{H})$ was deployed outdoors in the city of Jaén on December 2010. The outdoor calibration in STC of all the significant electrical parameters of these four thin film PV modules was carried out in the University of Jaén research facilities on October 2011, prior to the beginning of the experimental campaign to be detailed below. The most meaningful measured parameter for our purpose-the calibrated peak power $\left(P_{\mathrm{CAL}}^{*}\right.$, in $\left.\mathrm{W}\right)$ is shown in Table 1 . The nominal peak power, as provided by the manufacturer data sheets $\left(P_{\mathrm{NOM}}^{*}\right.$, in $\left.\mathrm{W}\right)$, is also provided in this table. A ten-month term ranging from December 2010 to October 2011 was considered a reasonable duration of the outdoor exposure to ensure the initial stabilization of the tested specimens. In fact, they underwent a new outdoor calibration in the same facilities after the completion of the aforementioned experimental campaign, in November 2012. Results gathered in Table 1 prove that this assumption was suitable for the objectives of our work. Consequently, the outdoor initial calibration values were assumed as the real peak power of each one of the CIGS, CdTe, and a-Si:H/ $\mu$ c$\mathrm{Si}: \mathrm{H}$ tested PV modules in the experimental results which are to be presented hereafter. The real peak power assumed for the a-Si:H specimen will be detailed in Section 3.3 in order to take into account the seasonal annealing which this material experiences over the year.

The used outdoor test and measurement research facilities are installed in the High Technical School building of the University of Jaén. An equator-facing open rack with a tilt angle of $35^{\circ}$ is mounted and located on 
the flat roof of this building. The four thin film PV modules were fixed on this open rack. The basic features of the test and measurement have been thoroughly described in some previous works $[26,27]$. Thus, the $I-V$ curve tracer system is based on a PVE PVPM 2540C capacitive load which is controlled by a PC running LabView. As the tracing curve process is underway the voltage-current pairs are recorded by means of two Agilent 34411A digital multimeters. The voltage and current data acquisition is synchronized thanks to an external trigger produced by an Agilent 33220A function generator so that the $I-V$ pairs are recorded at the same time. Additionally, the above four PV modules could be tested sequentially using this setup, as four switchgear boxes of solid state relays controlled by means of a multipurpose Agilent 34970A data acquisition/data logger switch unit provide this feature. Regarding environmental parameters, $G$ and $G(\lambda)$ are measured by means of a Kipp \& Zonnen CMP 21 pyranometer and an EKO MS700 spectroradiometer, respectively. Two four-wire resistive thermal detectors (RTD) Pt100 pasted at the back skin of each one of the PV modules aim at measuring the module temperature, while a Young $41382 \mathrm{VC}$ relative humidity and ambient temperature probe measures these two parameters. Finally, a Young 05305VM anemometer and a Vaisala barometric pressure sensor complete the experimental setup.

The $I$ - $V$ curve of each PV module together with the above parameters was periodically scanned every five minutes from November 2011 to October 2012, inclusive. Incident irradiance was measured at each $I-V$ point in order to check any changes in this environmental parameter that might exceed $2 \%$, due to transient cloud cover during measurement time. Measurements recorded in such changing environmental conditions have not been considered in the results to be presented hereafter. All these measurements have been taken during the time interval comprised between 10:00 and 14:00-the sun elevation is then higher than that of the rest of the day-so that the impact of the angle of incidence lends itself to be estimated in a simplified way, as shown in Section 3.3. Further, measurements with levels of $G$ below $300 \mathrm{~W} \cdot \mathrm{m}^{-2}$ have also been disregarded. Disregarding these measurements is justified since efficiency at low irradiance levels is hardly relevant $[28,29]$. Additionally, low levels of light could turn the inverter into a net energy consumer in grid-tied systems [29]. Then, as only poor contributions to the total electricity yield can be expected below $300 \mathrm{~W} \cdot \mathrm{m}^{-2}$ in sunny sites $[10,30]$, they have not been taken into account in this work. Additionally, this lower threshold allows omitting the performance losses of PV modules at low-light levels $[31,32]$.

2.3. Methodology. In this work, a short spectral characterisation of the collected irradiation over the experimental campaign is carried out first. Indeed, this characterisation proves to be useful to achieve a better understanding of some results shown later. Then, the influence of the module temperature and the spectral irradiance on the outdoor behaviour of the four tested PV modules is analysed in a qualitative way. This analysis is based on some contour graphs in which the module performance is depicted versus APE and $T_{\text {mod. }}$. In addition, PR over the experimental campaign is obtained for each tested PV module. Last, the impact of some phenomena that influence the performance of each considered PV technology over the 12-month test and measurement period-including module temperature and spectral effects-is quantified.

The output DC energy $\left(E_{\mathrm{DC}}\right.$, in Wh) delivered by each module during the 12-month experimental campaign was calculated by means of the integration of the maximum power obtained from each $I-V$ curve over 5-minute time intervals. The same method was also applied to stored values of $G-$ measured by means of a pyranometer-in order to calculate the incident irradiation $\left(H\right.$, in $\left.\mathrm{Wh} \cdot \mathrm{m}^{-2}\right)$ collected during these 12 months. The lower and upper limits of the considered interval of the spectrum $-a$ and $b$, in (1) - were set to 350 and $1050 \mathrm{~nm}$, respectively.

As commented in the previous section, data collected from November 2011 to October 2012, inclusive, have been used to produce the histogram and contour graphs to be shown next. These contour graphs depict the following, according to a colour code: (a) a matrix of $H$ and (b) matrices of PR, for each tested module. All these matrices have APE and $T_{\text {mod }}$ for row and column, respectively, with a grid mesh size of $1^{\circ} \mathrm{C} \times 0.005 \mathrm{eV}$.

The procedure to create the above contour graphs may be summarized as follows [18].

(1) The APE of $G$ is determined by the spectrum shape.

(2) The rows of both $H$ and $E_{\mathrm{DC}}$ are indexed by APE.

(3) The columns of both $H$ and $E_{\mathrm{DC}}$ are indexed by $T_{\text {mod }}$.

(4) The values of $H$ and the $E_{\mathrm{DC}}$ are added to the corresponding grid mesh. Then, incident irradiation for each grid mesh $\left(H_{\mathrm{GM}}\right.$, in Wh. $\left.\mathrm{m}^{-2}\right)$ and output $\mathrm{DC}$ energy for each grid mesh $\left(E_{\mathrm{DCGM}}\right.$, in $\left.\mathrm{Wh} \cdot \mathrm{m}^{-2}\right)$ are obtained

Then, grid-mesh performance ratio $\left(\mathrm{PR}_{\mathrm{GM}}\right)$, or performance ratio for each grid mesh, is calculated as follows:

$$
\mathrm{PR}_{\mathrm{GM}}=\frac{E_{\mathrm{DCGM}} / P_{\mathrm{NOM}}^{*}}{H_{\mathrm{GM}} / G^{*}},
$$

where $G^{*}$ is the incident irradiance at STC $\left(1000 \mathrm{~W} \cdot \mathrm{m}^{-2}\right)$. Values for $P_{\text {NOM }}^{*}[\mathrm{~W}]$ were drawn from the second column of Table 1.

\section{Results and Discussion}

Over 9,500 $I-V$ curves together with the same number of data corresponding to the different environmental factors listed in Section 2.2 were recorded for the tested CIGS, CdTe, and a$\mathrm{Si}: \mathrm{H} / \mu \mathrm{c}-\mathrm{Si}: \mathrm{H} \mathrm{PV}$ modules during the 12-month experimental campaign. However, only over 3,500 experimental samples like those previously described were selected from the whole data set for the tested a-Si:H PV module. These samples correspond to months ranging from December to March, inclusive (winter period, from now on). Approximately 
the same amount of these samples was selected for this module corresponding to months ranging from June to September, inclusive (summer period, from now on). Presenting and discussing the experimental results obtained for the a-Si:H PV module according to the winter and summer period is key to address the effects of seasonal annealing which this PV material experiences.

3.1. Spectral Characterisation of the Incident Irradiation Collected over the Experimental Campaign. Figure 2 depicts a histogram in which the percentage cumulative contribution of APE classes to $H$ collected over the 12-month experimental period is shown. Over $60 \%$ of this parameter has been generated with values of APE below $1.88 \mathrm{eV}$ (AM 1.5 G). This value is much higher than those reported for Kusatsu city (Japan, latitude $35^{\circ} \mathrm{N}$, longitude $136^{\circ} \mathrm{E}$ ) and Málaga (Spain, latitude $36^{\circ} \mathrm{N}$, longitude $4^{\circ} \mathrm{W}$ ) which are below $30 \%$ for equator-facing surfaces with a tilt angle somewhat lower than the local latitude $[21,27]$. This clearly indicates a higher red content of the spectral irradiance in Jaén than those of the other two sites, given the four-hour time window (10:0014:00) within which spectra were measured. The inland location of Jaén when compared to those of Kusatsu city and Málaga should be kept in mind. The lower humidity of the atmosphere in Jaén leads to a smaller absorption by water vapour. Consequently, the fraction of spectral irradiance at longer wavelengths is increased; this causes a relative "red-rich" spectrum [25]. This spectral feature of the site will allow us to explore how incident spectral irradiance distributions with APE lower than $1.85 \mathrm{eV}$ influence the tested PV specimens. It should be remembered again that previous works [18-20] have only dealt with APE values ranging from 1.85 to $2.03 \mathrm{eV}$.

Owing to the similarities found between the four contour graphs of $H_{\mathrm{GM}}$ collected over the experimental campaignone for each tested PV module, produced according to the methodology described in Section 2.3-only one of them is shown in Figure 3. Indeed, the peculiarities of this contour graph can be assumed for the four modules under test. The colour related to each grid mesh $-1^{\circ} \mathrm{C} \times 0.005 \mathrm{eV}$ in size-indicates the range of incident irradiation where the corresponding $H_{\mathrm{GM}}$ lies according to the colour code displayed on the right-hand side of Figure 3. The relatively low value of $H$ collected over the experimental campaignsome $600 \mathrm{kWh} \cdot \mathrm{m}^{-2}$-is due to the fact that the considered time window when data were recorded in this campaign spans from 10:00 to 14:00. It is also worth pointing out that only a negligible fraction of $H$ impinged on the modules under test at STC $\left(\mathrm{APE}=1.88 \mathrm{eV}\right.$ and $\left.T_{\bmod }=25^{\circ} \mathrm{C}\right)$.

3.2. Performance of the Tested PV Modules as a Function of the Average Photon Energy and Module Temperature. In this context, $\mathrm{PR}_{\mathrm{GM}}$ is an index that characterises the performance of a PV module at specific values of APE and $T_{\text {mod }}$, so that the influence of the irradiance intensity is negligible, given that measurements taken at incident irradiance levels below $300 \mathrm{~W} \cdot \mathrm{m}^{-2}$ have been left aside $[31,32]$. An expression related to $\mathrm{PR}_{\mathrm{GM}}$ shown below will be most helpful in the

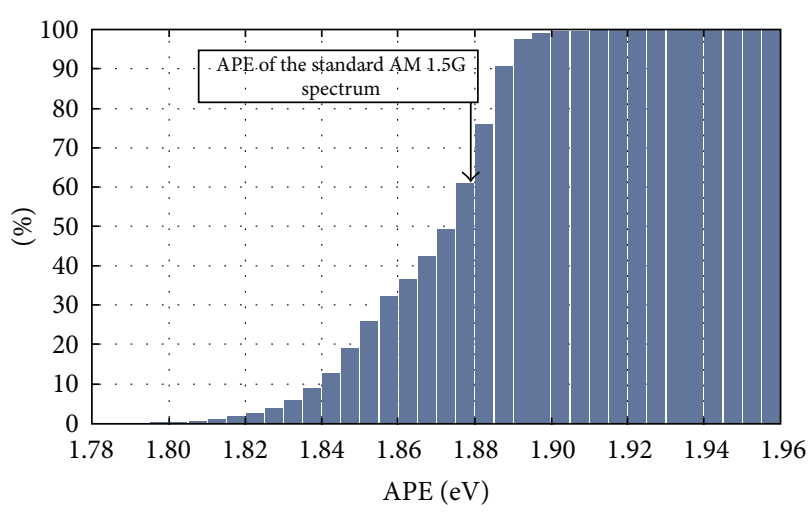

Figure 2: Percentage cumulative distribution of $H$ collected over the experimental campaign as a function of APE (class width $=0.005 \mathrm{eV}$ ).

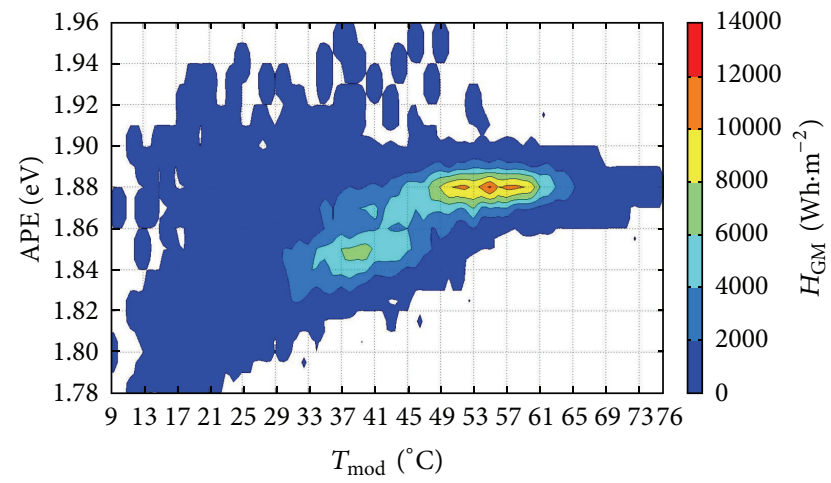

FIgURE 3: Contour graph of $H_{\mathrm{GM}}$ over the whole experimental campaign (November 2011-October 2012, inclusive) as a function of $T_{\text {mod }}$ and APE for the tested a-Si:H module. Blank areas indicate no data points.

discussion of results detailed hereafter. In this expression, some second-order effects are ignored-low performance at low-light levels as this is our case, AOI combined with dirt effects, and deviations of $P_{\mathrm{CAL}}^{*}$ from $P_{\mathrm{NOM}}^{*}$-in order to compromise accuracy in favour of simplicity. Thus, as a first approach, this index may be written as follows [33]:

$$
\mathrm{PR}_{\mathrm{GM}} \approx\left(1+\gamma\left(T_{\mathrm{mod}}-T_{\mathrm{mod}}^{*}\right)\right) \cdot \mathrm{SF}^{-1},
$$

where $\gamma\left[{ }^{\circ} \mathrm{C}^{-1}\right]$ is the maximum power temperature coefficient of the module, $T_{\bmod }^{*}\left[{ }^{\circ} \mathrm{C}\right]$ is the module temperature at STC, and $\mathrm{SF}^{-1}$ is the reciprocal of the spectral factor. The latter parameter may be written as

$$
\mathrm{SF}^{-1}=\frac{\int G(\lambda) \operatorname{SR}(\lambda) d \lambda \cdot \int G_{\mathrm{AM} 1.5 \mathrm{G}}(\lambda) d \lambda}{\int G_{\mathrm{AM} 1.5 \mathrm{G}}(\lambda) \operatorname{SR}(\lambda) d \lambda \cdot \int G(\lambda) d \lambda},
$$

where $G_{\mathrm{AM} 1.5 \mathrm{G}}(\lambda)\left[\mathrm{W} \cdot \mathrm{m}^{-2} \cdot \mathrm{nm}^{-1}\right]$ is the spectral irradiance of the standard AM $1.5 \mathrm{G}$ spectrum and $\operatorname{SR}(\lambda)$ is the relative spectral response of the PV device.

Values of $\mathrm{SF}^{-1}$ above 1 imply a better performance of the considered device under the actual spectrum than that 
achieved under the standard AM $1.5 \mathrm{G}$ spectrum if only spectral issues are considered. Conversely, values of $\mathrm{SF}^{-1}$ below 1 indicate a worse performance of the PV material under the actual spectrum when compared to the standard one, also assuming only spectral issues. Obviously, $\mathrm{SF}^{-1}$ higher than 1 implies spectral gains while $\mathrm{SF}^{-1}$ lower than 1 implies spectral losses.

Figures 4-6 show the contour graphs of $\mathrm{PR}_{\mathrm{GM}}$ for the tested CIGS, CdTe, and a-Si:H/ $\mu \mathrm{c}-\mathrm{Si}: \mathrm{H}$ PV modules as a function of $T_{\text {mod }}$ and APE. In these figures, some obvious spurious data points have been filtered. At first glance, these three contour graphs share a similar appearance leaving aside some differences which are to be discussed below. In fact, $\mathrm{PR}_{\mathrm{GM}}$ data points appear when $\mathrm{APE}$ ranges from 1.79 to $1.91 \mathrm{eV}$ at values of $T_{\text {mod }}$ below $25^{\circ} \mathrm{C}$, while these $\mathrm{PR}_{\mathrm{GM}}$ data points only appear within a much narrower interval of APE which varies between 1.86 and $1.90 \mathrm{eV}$ when $T_{\text {mod }}$ exceeds some $55^{\circ} \mathrm{C}$. Thus, some of the measured low incident irradiances-values of $G$ in the vicinity of $300 \mathrm{~W} \cdot \mathrm{m}^{-2}$-have been recorded under cloudy conditions. Under these conditions, transmission is enhanced in both the ultraviolet and blue range of the spectrum while water vapour absorption takes place at larger wavelength ranges [34]. Consequently, spectra obtained in overcast conditions are shifted to shorter wavelengths and lead to high values of APE. On the other hand, some of the data for these low incident irradiances have been recorded in the morning of clear and cold days, when the spectrum is redder than in the afternoon [35] so that this leads to lower values of APE down to $1.79 \mathrm{eV}$ and values of $T_{\text {mod }}$ below $25^{\circ} \mathrm{C}$. Measured high incident irradiancesover $600 \mathrm{~W} \cdot \mathrm{m}^{-2}$-are assumed to be related to fine weather. In such conditions, as raised by Ishii et al. [25], the Rayleigh scattering which leads to an increase/decrease of the spectral irradiance at shorter wavelengths below $700 \mathrm{~nm}$ is balanced by the increase/decrease of "red" light due to water vapour absorption. This "offset effect" keeps values of APE within a relatively small interval around $1.88 \mathrm{eV}$. This interval gets even narrower-it varies between some 1.87 and $1.89 \mathrm{eV}$ - as incident irradiance exceeds some $900 \mathrm{~W} \cdot \mathrm{m}^{-2}$, a fact which is highly correlated with relatively high module temperaturesthat is, $T_{\text {mod }}$ above some $60^{\circ} \mathrm{C}$-in hot and sunny climates such as that of Jaén.

Figures 7 and 8 depict the contour plots of $\mathrm{PR}_{\mathrm{GM}}$ for the a-Si:H PV tested module in the winter and summer periods, respectively. The shape of the contour graph shown in Figure 7-winter period-resembles those of Figures 4-6. However, the values of $\mathrm{PR}_{\mathrm{GM}}$ obtained in the winter period take place at APE below $1.88 \mathrm{eV}$, which indicates a prevailing red-rich spectrum in this season. Only some sixty values of $\mathrm{PR}_{\mathrm{GM}}$ at $\mathrm{APE}$ above $1.88 \mathrm{eV}$ were obtained. In fact, these values are omitted in Figure 7 due to their minor relevance, when compared to the remaining 3,500 points represented in the graph. On the other hand, the contour graph of Figure 8summer period-shows how a sizeable number of values of $\mathrm{PR}_{\mathrm{GM}}$ take place at APE above $1.88 \mathrm{eV}$. Consequently, spectra shifted to shorter wavelengths play an important role in the hot season. The "red-richness" of the solar spectra recorded in the winter period owes a good deal to the sun altitude. In fact,

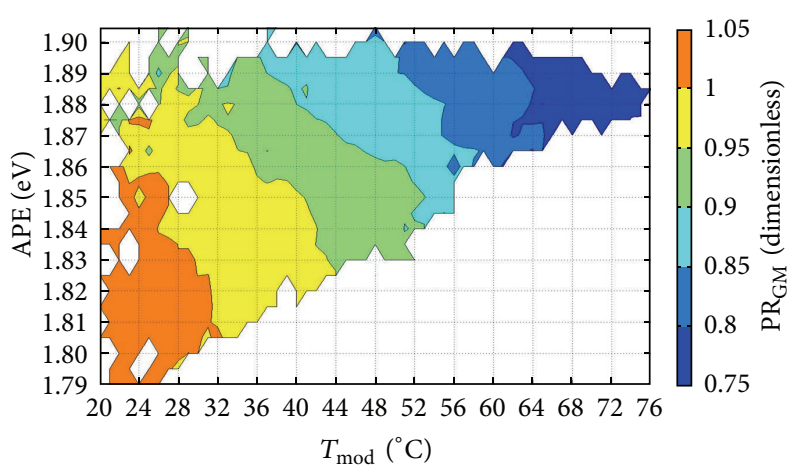

FIGURE 4: Contour graph of $\mathrm{PR}_{\mathrm{GM}}$ of the tested CIGS PV module as a function of $T_{\bmod }$ and APE. Blank areas indicate no data points.

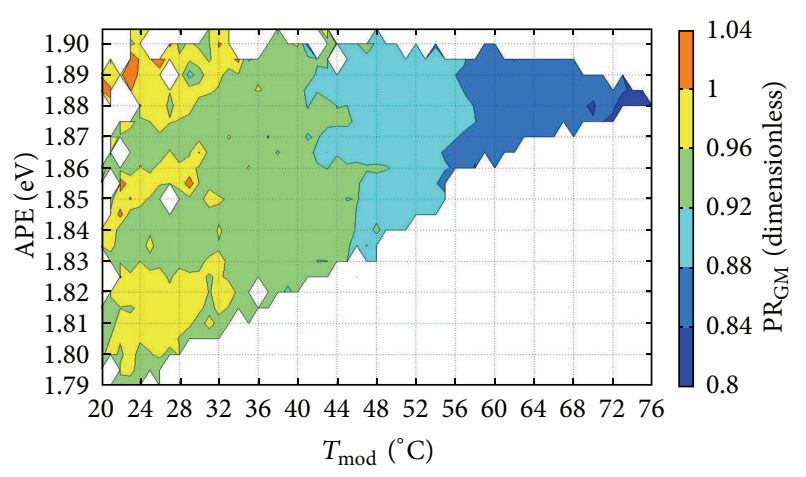

FIGURE 5: Contour graph of $\mathrm{PR}_{\mathrm{GM}}$ of the tested CdTe PV module as a function of $T_{\text {mod }}$ and APE. Blank areas indicate no data points.

the sun altitude is lower in the cold season than in the warm one, so that this fact gives rise to higher values of the optical air mass (OAM), when compared to summer ones. Hence, long wavelength light is enhanced in the winter period, so that low values of APE are obtained.

Regarding seasonal annealing, comparing some areas of Figures 7 and 8 allows identifying this phenomenon in the tested a-Si:H PV module. Thus, in Figure 7-winter periodmost values of $\mathrm{PR}_{\mathrm{GM}}$ vary between 0.88 and 0.92 within the stripe where APE and $T_{\text {mod }}$ range from 1.86 to $1.87 \mathrm{eV}$ and from 45 to $57^{\circ} \mathrm{C}$, respectively. However, most values of $\mathrm{PR}_{\mathrm{GM}}$ lie in the interval 0.92 to 0.96 within the stripe determined by the same range of APE and $T_{\bmod }$ in the summer period (Figure 8).

Contour graphs depicted in Figures 4-8 provide us with some qualitative information to assess the influence of module temperature, which is first discussed below. Then, the impact of the spectral irradiance distribution by means of APE is to be analysed.

(a) Module temperature turns out to exert a limited influence on the performance of the a-Si: $\mathrm{H}, \mathrm{CdTe}$, and a-Si:H/ $\mu \mathrm{c}-\mathrm{Si}: \mathrm{H}$ modules. This stems from scanning Figures 5, 6, 7, and 8 in the horizontal direction, at a given fixed APE. According to (3), the explanation of this behaviour lies in the low maximum power 


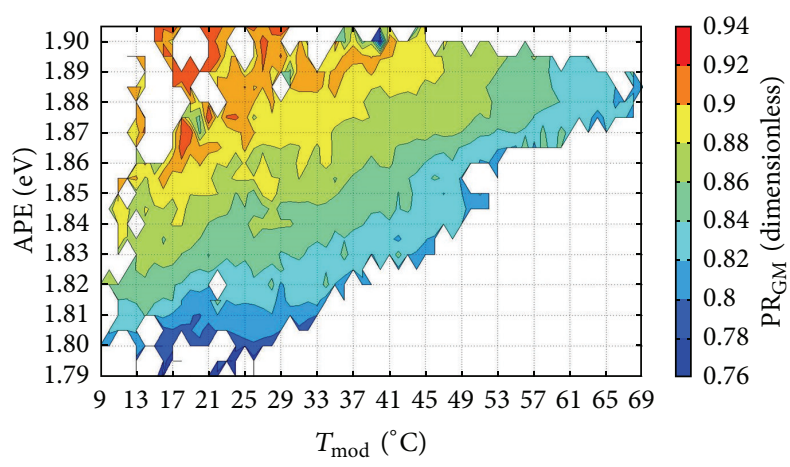

FIGURE 6: Contour graph of $\mathrm{PR}_{\mathrm{GM}}$ of the tested a-Si:H/ $\mu \mathrm{c}-\mathrm{Si}: \mathrm{H} \mathrm{PV}$ module as a function of $T_{\bmod }$ and APE. Blank areas indicate no data points.

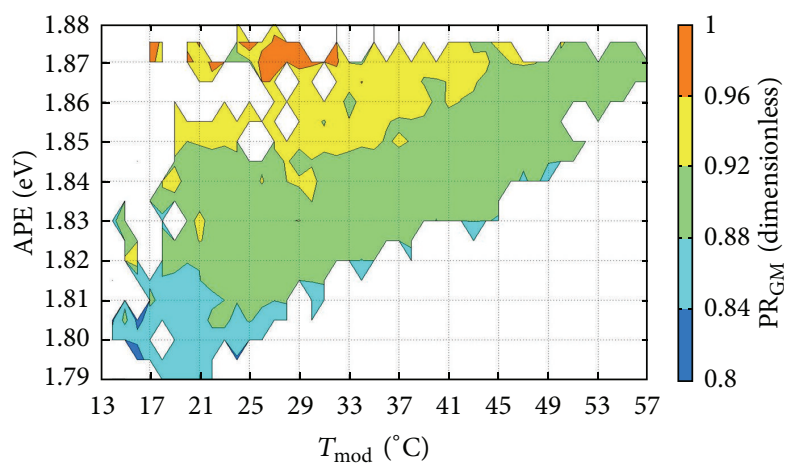

Figure 7: Contour graph of $\mathrm{PR}_{\mathrm{GM}}$ of the tested a-Si:H PV module as a function of $T_{\text {mod }}$ and APE for the winter period. Blank areas indicate no data points.

temperature coefficients of these modules when compared to those of modules based on c-Si technologies. Thus, $\gamma$ equals $-0.0023,-0.0025$, and $-0.0024^{\circ} \mathrm{C}^{-1}$ for the tested a-Si:H, CdTe, and a-Si:H/ $\mu$ c-Si:H specimens, as provided by their manufacturers' data sheets. Regarding c-Si, a typical average value of $-0.0040^{\circ} \mathrm{C}^{-1}$ can be assumed for $\gamma$ [36]. However, the value provided by the CIGS module manufacturer for this parameter $\left(-0.0045^{\circ} \mathrm{C}^{-1}\right)$ helps to explain the noticeable impact of $T_{\text {mod }}$ on the outdoor performance of this module. This is also derived from scanning Figure 4 in the horizontal direction, at a given fixed APE.

(b) Regarding the spectral incident irradiance distribution, both a-Si:H and a-Si:H/ $\mu \mathrm{c}-\mathrm{Si}: \mathrm{H}$ specimens are very sensitive to variations of the shape of the spectrum. This can be easily noticed in Figures 6, 7 , and 8 , since increasing values of APE-given a fixed module temperature-lead to higher values of $\mathrm{PR}_{\mathrm{GM}}$, as a general trend. Doubtless, high spectral gains cause this behaviour, as values of $\mathrm{SF}^{-1}$ above 1.1 have been reported when the solar spectrum shifts to the blue [25]. Broadly speaking, blue-rich spectra

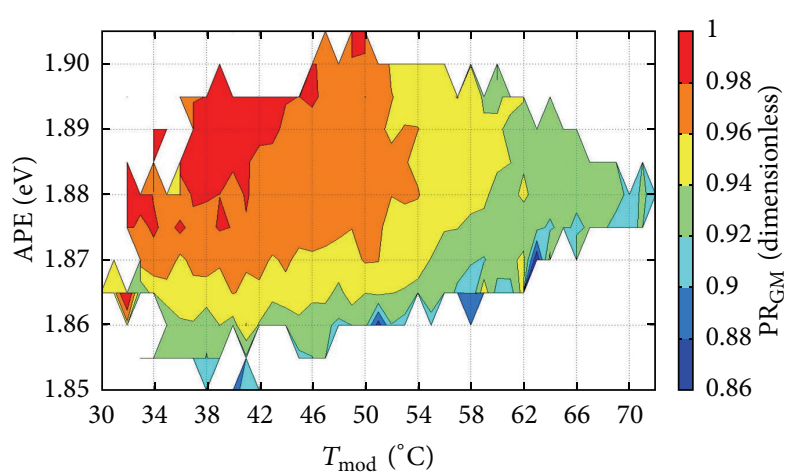

FIGURE 8: Contour graph of PR of the tested a-Si:H PV module as a function of $T_{\text {mod }}$ and APE for the summer period. Blank areas indicate no data points.

cause spectral gains in the a-Si:H and a-Si:H/ $\mu \mathrm{c}-$ $\mathrm{Si}: \mathrm{H}$ modules, according to (3). Nevertheless, the CIGS module is also very sensitive to the spectral incident irradiance in an opposite way: decreasing values of APE - given a fixed module temperaturelead to higher values of $\mathrm{PR}_{\mathrm{GM}}$, also as a general trend. Figure 4 also shows how this performance parameter is greater than 1 within some specific areas of the contour graph where APE is lower than $1.86 \mathrm{eV}$; spectral gains doubtless explain this, together with low values of $T_{\text {mod }}$. Contrary to the a-Si:H and a-Si:H/ $\mu \mathrm{c}-$ $\mathrm{Si}: \mathrm{H}$ specimens-and also broadly speaking-bluerich spectra cause spectral losses in the CIGS module performance, bearing in mind (3). Last, Figure 5 shows how the CdTe specimen is not so sensitive to APE, especially when $T_{\text {mod }}$ exceeds a certain threshold; this can be easily checked by scanning this figure in the vertical direction at a fixed $T_{\bmod }$, when this parameter is greater than some $35^{\circ} \mathrm{C}$.

3.3. Assessment of the Impact of Phenomena Influencing Performance Ratio over the Experimental Campaign. A qualitative analysis on the influence of the solar spectrum distribution and module temperature on the considered PV modules has been presented in Section 3.2. However, in this section, we attempt to quantitatively assess the impact of these two factors on the performance of the four tested PV modules over the experimental campaign. Thus, in general, five phenomenawhich generally cause performance losses-mainly influence the outdoor behaviour of PV modules:
(a) low performance at low-light levels,
(b) AOI combined with dirt effects,
(c) module temperature effects,
(d) deviations of $P_{\mathrm{CAL}}^{*}$ from $P_{\mathrm{NOM}}^{*}$,
(e) spectral effects.

Additionally, the a-Si:H PV module is subject to seasonal annealing, which must be properly addressed.

The effects of the above phenomena overlap over time and sometimes are rather difficult to clearly be distinguished. 
This is why the experimental campaign was arranged in a way that is relatively simple to quantify the impact of both module temperature and irradiance spectral distribution. Thus, since all data were recorded at incident irradiance below $300 \mathrm{~W} \cdot \mathrm{m}^{-2}$, low performance related to low-light levels is disregarded here [31, 32]. Also, the effects of dirt have been neglected in what follows; in fact, modules were cleaned manually at least once a month, except under rainy weather.

Leaving aside these two phenomena simplifies the way to make a quantitative estimation of the impact of the remaining ones on the outdoor behaviour of the tested PV specimens. Indeed, the used procedure to quantify these effects is detailed below.

If the module peak power is assumed to be equal to $P_{\mathrm{NOM}}^{*}$, nominal energy $\left(E_{N}\right.$, in $\left.\mathrm{Wh}\right)$ is stated as the energy which the tested PV module would have delivered over the experimental campaign if the module had ideally operated without any losses, with $T_{\bmod }=25^{\circ} \mathrm{C}$ and the same solar irradiation during that period of time:

$$
E_{N}=\frac{1}{12} \cdot \frac{P_{\mathrm{NOM}}^{*}}{G^{*}} \sum_{i=1}^{N} G_{i}(\mathrm{Wh}),
$$

where $G_{i}\left[\mathrm{~W} \cdot \mathrm{m}^{-2}\right]$ is the $i$ th measured value of the incident irradiance and $N$ is the number of measured values. Factor $1 / 12$ is used to reconcile units, keeping in mind that the samples were recorded every five minutes.

The final energy $\left(E_{F}\right.$, in Wh) is stated as the energy that the tested PV module actually delivered over the experimental campaign, and it may be written as

$$
E_{F}=\frac{1}{12} \sum_{i=1}^{N} P_{\mathrm{DC}, i}(\mathrm{Wh}),
$$

where $P_{\mathrm{DC}, i}$ is the $i$ th measured value of the maximum power delivered by the PV module.

Obviously, PR is the ratio of $E_{F}$ to $E_{N}$. It is commonly accepted to express this ratio in percentage units, so that it may be written as

$$
\mathrm{PR}=\frac{E_{F}}{E_{N}} \cdot 100(\%)
$$

Temperature losses are obtained by calculating the difference between temperature-corrected $E_{F}$ and $E_{F}$ itself. For convenience purposes, these temperature losses $\left(L_{T \text { mod }}\right)$ are expressed in this work in percentage units, relative to $E_{N}$ :

$$
\begin{aligned}
L_{T \bmod }= & \frac{1}{12} \sum_{i=1}^{N} P_{\mathrm{DC}, i}\left(\frac{1}{1+\gamma\left(T_{\bmod , i}-T_{\bmod }^{*}\right)}-1\right) \\
& \div E_{N} \cdot 100(\%)
\end{aligned}
$$

where $T_{\bmod , i}$ is the $i$ th measured value of the module temperature. For each module, values of $\gamma$ as provided by the manufacturer datasheets are used here.

Losses derived from differences between $P_{\mathrm{CAL}}^{*}$ and $P_{\mathrm{NOM}}^{*}$ are obtained by multiplying temperature-corrected $E_{F}$ by a factor that takes into account this phenomenon. Also, for
TABLE 2: Values of the incident angle modifier for solstices and equinoxes at 10:00, 12:00, and 14:00 $\left(\omega=-30^{\circ}, 0^{\circ}\right.$, and $30^{\circ}$, resp. $)$.

\begin{tabular}{lccc}
\hline & $\omega\left[^{\circ}\right]$ & $\theta_{s}\left[^{\circ}\right]$ & IAM $\left(\theta_{s}\right)$ \\
\hline Summer and & -30 & 37.4 & 0.98 \\
winter solstices & 0 & 23.5 & 0.99 \\
& 30 & 37.4 & 0.98 \\
\hline Autumn and & -30 & 30 & 0.99 \\
spring equinoxes & $0^{\circ}$ & 0 & 1 \\
& 30 & 30 & 0.99 \\
\hline
\end{tabular}

convenience purposes, these losses due to the deviation of $P_{\mathrm{CAL}}^{*}$ from $P_{\mathrm{NOM}}^{*}\left(L_{P_{\mathrm{CAL}}^{*} \neq P_{\mathrm{NOM}}^{*}}\right)$ are expressed in this work in percentage units, relative to $E_{N}$ :

$$
\begin{aligned}
& L_{P_{\mathrm{CAL}}^{*}} \neq P_{\mathrm{NOM}}^{*} \\
& =\frac{1}{12} \sum_{i=1}^{N} \frac{P_{\mathrm{DC}, i}}{1+\gamma\left(T_{\mathrm{mod}}-T_{\mathrm{mod}}^{*}\right)}\left(\frac{P_{\mathrm{NOM}}^{*}}{P_{\mathrm{CAL}}^{*}}-1\right) \\
& \quad \div E_{N} \cdot 100(\%) .
\end{aligned}
$$

Regarding the optical losses experienced by the PV modules, a popular formula for the incident angle modifier $\left(\operatorname{IAM}\left(\theta_{s}\right)\right)$ or relative transmittance is widely used, normalized by the total transmittance for normal incidence, where $\theta_{s}\left[{ }^{\circ}\right]$ is the angle of incidence between the rays of the sun and the normal to the surface. This is an expression [37] proposed by the American Society of Heating Refrigerating and Air Conditioning Engineers (ASHRAE):

$$
\operatorname{IAM}\left(\theta_{s}\right)=1-b_{0}\left(\frac{1}{\cos \theta_{s}}-1\right),
$$

where $b_{0}$ is an empirical coefficient determined for each type of PV module. When unknown, as this is our case, a general value of $b_{0}=0.07$ may be assumed. Equation (10) is applied to direct and circumsolar irradiances, while an approximate constant of 0.9 is used with isotropic and reflected irradiances [36].

Since the tested PV modules were deployed in the Northern Hemisphere on a south-oriented surface with a tilt angle $\left(35^{\circ}\right)$ very close to the latitude $\left(37^{\circ} \mathrm{N}\right)$, it may be assumed that $[36]$

$$
\cos \theta_{s}=\cos \delta \cos \omega
$$

where $\delta\left[{ }^{\circ}\right]$ is the solar declination and $\omega\left[{ }^{\circ}\right]$ is the true solar time: $\omega=0^{\circ}$ at noon and is counted negative in the morning and positive in the afternoon. Given that experimental data have been recorded daily at 5-minute intervals from 10:00 $\left(\omega=-30^{\circ}\right)$ to $14: 00\left(\omega=30^{\circ}\right)$, Table 3 gathers some relevant values related to the optical losses experienced by the tested PV modules.

From Table 2, it is clear that $\theta_{s}$ varied over our experimental campaign between 0 and $37.4^{\circ}$, which correspond to values of $\operatorname{IAM}\left(\theta_{s}\right)$ ranging from 1 to 0.98 , respectively. Then, a reasonable value to take into account the effects of 
TABLE 3: Values of performance ratio and different performance losses experienced by the four tested PV modules over the experimental campaign.

\begin{tabular}{|c|c|c|c|c|c|}
\hline & PR (\%) & $L_{T_{\bmod }}(\%)$ & $L_{P_{\mathrm{CAL}}^{*}} \neq P_{\mathrm{NOM}}^{*}(\%)$ & $L_{\mathrm{AOI}}(\%)$ & $L_{\text {Spec }}(\%)$ \\
\hline CIGS & 89.4 & 10.3 & 0.8 & 1.0 & -1.5 \\
\hline $\mathrm{CdTe}$ & 91.1 & 4.8 & 3.6 & 0.9 & -0.4 \\
\hline $\mathrm{Si}: \mathrm{H} / \mu \mathrm{c}-\mathrm{Si}: \mathrm{H}$ & 85.9 & 3.8 & 8.7 & 1.0 & 0.6 \\
\hline a-Si : H (winter) & 88.4 & 2.2 & 4.4 & 1.0 & 4.0 \\
\hline a-Si:H (summer) & 95.4 & 7.0 & 0.7 & 1.0 & -4.1 \\
\hline
\end{tabular}

the AOI on an annual basis is 0.99 . Indeed, albedo can be neglected in most PV calculations [36]; in our case, the flat roof ground where the PV modules are deployed has a very dark ochre colour. Besides, direct and circumsolar irradiation highly prevails in sunny climates such as that of Jaén.

Taking into account all the above considerations, the AOI losses $\left(L_{\mathrm{AOI}}\right)$ are expressed in this work in percentage units, relative to $E_{N}$, too, as follows:

$$
\begin{aligned}
L_{\mathrm{AOI}}= & \frac{1}{12} \cdot \sum_{i=1}^{N} \frac{P_{\mathrm{DC}, i}}{1+\gamma\left(T_{\mathrm{mod}}-T_{\mathrm{mod}}^{*}\right)} \\
& \cdot \frac{P_{\mathrm{NOM}}^{*}}{P_{\mathrm{CAL}}^{*}} \cdot\left(\frac{1}{0.99}-1\right) \div E_{N} \cdot 100(\%) .
\end{aligned}
$$

Last, the estimation of spectral losses $\left(L_{\mathrm{Spec}}\right)$ is rather straightforward, expressed in percentage units, relative to $E_{N}$, as well:

$$
\begin{aligned}
L_{\mathrm{Spec}}= & 100-\mathrm{PR}(\%)-L_{T_{\mathrm{mod}}} \\
& -L_{P_{\mathrm{CAL}}^{*} \neq P_{\mathrm{NOM}}^{*}}-L_{\mathrm{AOI}}(\%) .
\end{aligned}
$$

Table 3 gathers the values of $\mathrm{PR}, L_{T_{\bmod }}, L_{P_{\mathrm{CAL}}^{*} \neq P_{\mathrm{NOM}}^{*}}, L_{\mathrm{AOI}}$, and $L_{\text {Spec }}$ derived from the experimental data collected from November 2011 to October 2012, inclusive. Values of $P_{\mathrm{CAL}}^{*}$ have been drawn from the third column of Table 1-initial calibration-in order to calculate $L_{P_{\mathrm{CAL}}^{*} \neq P_{\mathrm{NOM}}^{*}}$ for the CIGS, $\mathrm{CdTe}$, and a-Si:H/ $\mu \mathrm{c}-\mathrm{Si}: \mathrm{H}$ PV tested modules, by means of (9). Regarding the a-Si:H specimen, seasonal annealing causes a module power variation during its outdoor exposure. Thus, the peak power of this module was calibrated at the beginning of each month during the winter and summer periods, from December to March, inclusive, and from June to September, inclusive, respectively. Accordingly, the average values of these calibrated peak power data have been used to calculate $L_{P_{\mathrm{CAL}}^{*} \neq P_{\mathrm{NOM}}^{*}}$ for each season. Indeed, average values of 54.6 and $58.6 \mathrm{~W}$ were used for $P_{\mathrm{CAL}}^{*}$ in the winter and summer periods, respectively.

The especially noticeable deviation of $P_{\mathrm{CAL}}^{*}$ from $P_{\mathrm{NOM}}^{*}$ in the a-Si:H/ $\mu \mathrm{c}-\mathrm{Si}: \mathrm{H}$ PV module-the reader is referred to Table 1 -causes the high value obtained for $L_{P_{\mathrm{CAL}}^{*} \neq P_{\mathrm{NOM}}^{*}}$ for this specimen. On the other hand, the seasonal annealing experienced by the a-Si:H material is reflected in the oscillation of $L_{P_{\text {CAL }}^{*} \neq P_{\mathrm{NOM}}^{*}}$ between $0.7 \%$-summer periodand $7 \%$-winter period. Besides, all the tested modules experience similar losses related to AOI ( 1\%).
As it could be easily anticipated due to its module maximum power temperature coefficient $\left(-0.0045^{\circ} \mathrm{C}^{-1}\right.$, according to manufacturer's data sheets), the CIGS module is the most affected by losses caused by values of $T_{\text {mod }}$ other than $25^{\circ} \mathrm{C}$ (10.3\%). The remaining modules are less sensitive to the impact of this parameter, due to their lower values of $\gamma$, as commented in Section 3.2.

Spectral losses are scarcely relevant, in general, for the CIGS, CdTe, and a-Si:H/ $\mu \mathrm{c}-\mathrm{Si}: \mathrm{H}$ PV tested modules. Anyway, it is worth noting that spectral losses turn into gainsnegative values of parameter $L_{\mathrm{Spec}}-$ for the CdTe and, above all, for the CIGS PV module. As commented in Section 3.2Figure 4-the performance of this module is enhanced when the spectrum shifts to longer wavelengths. This fact, combined with the prevailing "red-richness" of the solar spectra recorded over the experimental campaign, as derived from Figure 1, is the logical explanation of the annual spectral gains (1.5\%) experienced by the CIGS material. On the other hand, the a-Si:H module behaves in an opposite way from a spectral point of view. As shorter wavelengths of the spectra are enhanced in the summer period, this material experiences noticeable spectral gains (4.1\%) due to its good performance under "blue-rich" spectra. These gains turn to losses in the winter period (4.0\%). Anyway, it should be remembered that longer considered time intervals reduce spectral effects [38]. Thus, although not shown in Table $3, L_{\text {Spec }}$ calculated for the CIGS PV module from December to March, inclusive, equals $-3.9 \%$-that is, spectral gains-while this parameter rises up to $3.4 \%$ - that is, spectral losses-when calculated from June to September, inclusive. Likewise-not shown in Table 3, either $-L_{\text {Spec }}$ equals $1.0 \%$ when calculated over the 12 months of the experimental campaign for the a-Si:H PV module.

\section{Conclusions}

The influence of module temperature and solar spectrum distribution on the outdoor performance of four thin film PV modules-a sample for each one of four considered technologies (a-Si:H, CIGS, CdTe, and a-Si:H/ $\mu \mathrm{c}-\mathrm{Si}: \mathrm{H})-$ has been explored by means of an experimental campaign arranged so that $60 \%$ of the collected incident irradiation over 12 months has been generated under solar spectra whose long wavelength light is enhanced, when compared to the AM 1.5G incident spectral irradiance distribution. In this sense, the inland climate of the site where the experimental campaign took place has allowed us to study the outdoor behaviour of the four tested modules under a "red-rich" solar 
spectrum. This has paved the way to analyse this behaviour under values of APE-ranging from 1.79 to $1.91 \mathrm{eV}$-lower than those explored in previous works-ranging from 1.85 to $2.03 \mathrm{eV}$-aiming at the same direction [18-20]. For each one of these technologies, a contour graph was obtained in which the module performance is depicted versus APE and $T_{\text {mod }}$. Despite not being an original approach, no such contour graphs have been produced yet for CIGS and CdTe modules, as far as we know. These figures have allowed us to carry out a qualitative analysis of the impact of module temperature and the spectrum shape on the performance of the tested PV modules.

(a) The performance of the tested a-Si:H, CdTe, and a$\mathrm{Si}: \mathrm{H} / \mu \mathrm{c}-\mathrm{Si}: \mathrm{H}$ modules shows little sensitivity to $T_{\bmod }$ due to their low maximum power temperature coefficients. The higher value provided for this parameter by the manufacturer of the CIGS module explains why this device performs worse as $T_{\bmod }$ increases, at fixed APE.

(b) Both the a-Si:H and a-Si:H/ $\mu \mathrm{c}-\mathrm{Si}: \mathrm{H}$ modules noticeably improve their outdoor performance as APE increases-the solar spectral incident irradiance is enhanced at short wavelengths - at fixed $T_{\bmod }$. The trend is the other way round for the CIGS module; at fixed $T_{\text {mod }}$, its performance worsens as APE increases; that is, the solar spectral incident irradiance is enhanced at long wavelengths. Last, the CdTe PV module does not show such a strong dependence on this spectral index as the other PV specimens do.

Additionally, PR over the experimental campaign has been calculated for each tested PV module. Also, the impact of some phenomena influencing this index for each considered PV technology over the 12-month test and measurement period has been quantified and discussed.

The especially noticeable deviation of $P_{\mathrm{CAL}}^{*}$ from $P_{\mathrm{NOM}}^{*}$ in the a-Si:H/ $\mu$ c-Si:H PV module causes the most remarkable losses due to this phenomenon (8.7\%). On the other hand, the seasonal annealing experienced by the a-Si:H material is reflected in the oscillation of these kinds of losses between $0.7 \%$ - summer period-and $7 \%$ - winter period. Nevertheless, all the tested modules experience similar losses related to the impact of the angle of incidence $(\sim 1 \%)$.

As it could be easily predicted, given its module maximum power temperature coefficient, the CIGS module is the most affected by temperature losses (10.3\%). The remaining modules are less sensitive to variations in module temperature, due to their lower values of $\gamma$.

Taking an overall view, spectral losses or gains are scarcely relevant-below 1.5\% - in general, for all the tested modules when an annual basis is considered. This is not the case when the time interval of integration to calculate spectral effects is lowered down to four months.

Small annual spectral losses are experienced by the CdTe PV module (0.4\%) and also small annual spectral gains are experienced by the CdTe specimen $(0.6 \%)$. These gains rise up to $1.5 \%$ for the CIGS PV module; this is the consequence of the improved performance of this module under long wavelength light, as commented above, combined with the "red-richness" of the solar spectra recorded over the experimental campaign. Since the a-Si:H PV module behaves in an opposite way from a spectral point of view, its spectral losses are equal to $1 \%$ on an annual basis.

The impact of the spectrum is more noticeable when time intervals shorter than a year are considered. Spectral gains calculated for the CIGS PV module from December to March, inclusive, equal 3.9\% while these gains turn to losses $(3.4 \%)$ when calculated from June to September, inclusive. On the other hand, the a-Si:H PV module experiences spectral losses of $4.0 \%$ and spectral gains of $4.1 \%$ for the winter and summer periods, respectively.

Anyway, the small size of the sample and the relatively limited amount of available data-only a module from a specific manufacturer of each one of the four studied technologies, experiencing a 12-month outdoor exposure in a specific sunny suite-suggest using the above conclusions with caution. However, it should be remembered that many valuable contributions have gathered some sound conclusions on thin film PV module outdoor performance using measurements drawn from only one specimen $[13-16,18,24$, 39-41].

\section{Abbreviations}

Terminology

\begin{tabular}{|c|c|}
\hline AM: & Air mass \\
\hline ASHRAE: & $\begin{array}{l}\text { American Society of Heating Refrigerating } \\
\text { and Air Conditioning Engineers }\end{array}$ \\
\hline a-Si:H: & Hydrogenated amorphous silicon \\
\hline a-Si:H/ $\mu c-S i: H:$ & Hydrogenated amorphous \\
\hline & $\begin{array}{l}\text { silicon/hydrogenated microcrystalline } \\
\text { silicon hetero-Junction }\end{array}$ \\
\hline CdTe: & Cadmium telluride \\
\hline CIGS: & Copper indium gallium selenide sulfide \\
\hline c-Si: & Crystalline silicon \\
\hline IEC: & International Electrotechnical \\
\hline & Commission \\
\hline PC: & Personal computer \\
\hline PV: & Photovoltaic(s) \\
\hline PVGCS: & PV grid-connected system(s) \\
\hline RTD: & Resistive thermal detector \\
\hline STC: & Standard test conditions. \\
\hline
\end{tabular}

Symbols

a: Lower wavelength limit of an interval of the spectrum [nm]

AOI: Angle of incidence (in general) $\left[{ }^{\circ}\right]$

APE: Average photon energy $[\mathrm{eV}]$

$b$ : Upper wavelength limit of an interval of the spectrum [nm]

$b_{0}$ : Empirical coefficient determined for each type of PV module

$E_{\mathrm{DC}}$ : Output DC energy [Wh] 


\begin{tabular}{|c|c|}
\hline$E_{\mathrm{DCGM}}:$ & $\begin{array}{l}\text { Output DC energy for each grid mesh } \\
{\left[\mathrm{Wh} \cdot \mathrm{m}^{-2}\right]}\end{array}$ \\
\hline$E_{F}:$ & Final energy $[\mathrm{Wh}]$ \\
\hline$E_{N}:$ & Nominal energy [Wh] \\
\hline$G:$ & Incident irradiance $\left[\mathrm{W} \cdot \mathrm{m}^{-2}\right]$ \\
\hline$G(\lambda):$ & $\begin{array}{l}\text { Incident spectral irradiance } \\
{\left[\mathrm{W} \cdot \mathrm{m}^{-2} \cdot \mathrm{nm}^{-1}\right]}\end{array}$ \\
\hline$G^{*}:$ & $\begin{array}{l}\text { Incident irradiance at standard test } \\
\text { conditions }\left[1000 \mathrm{~W} \cdot \mathrm{m}^{-2}\right]\end{array}$ \\
\hline$G_{\mathrm{AM} 1.5}(\lambda):$ & $\begin{array}{l}\text { Incident spectral irradiance of the } \\
\text { standard AM } 1.5 \mathrm{G} \text { spectrum } \\
{\left[\mathrm{W} \cdot \mathrm{m}^{-2} \cdot \mathrm{nm}^{-1}\right]}\end{array}$ \\
\hline$G_{i}:$ & $\begin{array}{l}\text { The } i \text { th measured value of the incident } \\
\text { irradiance }\end{array}$ \\
\hline$H:$ & Incident irradiation $\left[\mathrm{Wh} \cdot \mathrm{m}^{-2}\right]$ \\
\hline$H_{\mathrm{GM}}:$ & $\begin{array}{l}\text { Incident irradiation for each grid mesh } \\
{\left[\mathrm{Wh} \cdot \mathrm{m}^{-2}\right]}\end{array}$ \\
\hline$I:$ & Current $[\mathrm{A}]$ \\
\hline $\operatorname{IAM}\left(\theta_{s}\right)$ : & Incident angle modifier \\
\hline$L_{\mathrm{AOI}}:$ & Angle of incidence losses \\
\hline$L_{P_{\mathrm{CAL}}^{*}}^{*} \neq P_{\mathrm{NOM}}^{*}:$ & $\begin{array}{l}\text { Losses due to deviation of the calibrated } \\
\text { peak power of a PV module from its } \\
\text { nominal peak power }\end{array}$ \\
\hline$L_{\text {Spec }}:$ & Spectral losses \\
\hline$L_{T \bmod }:$ & Temperature losses \\
\hline$N:$ & $\begin{array}{l}\text { Number of measured values (of incident } \\
\text { irradiance or maximum power delivered } \\
\text { by the PV module) }\end{array}$ \\
\hline$P_{\mathrm{CAL}}^{*}:$ & $\begin{array}{l}\text { Calibrated peak power of a PV } \\
\text { module }[\mathrm{W}]\end{array}$ \\
\hline$P_{\mathrm{NOM}}^{*}:$ & $\begin{array}{l}\text { Nominal peak power of a PV module (as } \\
\text { provided by the manufacturer data sheets) } \\
{[\mathrm{W}]}\end{array}$ \\
\hline$P_{\mathrm{DC}, i}:$ & $\begin{array}{l}\text { The } i \text { th measured value of the maximum } \\
\text { power delivered by the PV module [W] }\end{array}$ \\
\hline PR: & (Module) performance ratio \\
\hline $\mathrm{PR}_{\mathrm{GM}}:$ & (Module) grid-mesh performance ratio \\
\hline SF: & Spectral factor \\
\hline $\operatorname{SR}(\lambda):$ & Relative spectral response \\
\hline$T_{\mathrm{amb}}:$ & Ambient temperature $\left[{ }^{\circ} \mathrm{C}\right]$ \\
\hline$T_{\text {mod }}:$ & Module temperature $\left[{ }^{\circ} \mathrm{C}\right]$ \\
\hline$T_{\bmod }^{*}:$ & Module temperature at STC $\left[{ }^{\circ} \mathrm{C}\right]$ \\
\hline$T_{\bmod , i}:$ & $\begin{array}{l}\text { The } i \text { th measured value of module } \\
\text { temperature }\left[{ }^{\circ} \mathrm{C}\right]\end{array}$ \\
\hline$V:$ & Voltage $[\mathrm{V}]$ \\
\hline$\gamma:$ & $\begin{array}{l}\text { Module maximum power temperature } \\
\text { coefficient }\left[{ }^{\circ} \mathrm{C}^{-1}\right]\end{array}$ \\
\hline$\delta:$ & Solar declination $\left[{ }^{\circ}\right]$ \\
\hline$\theta_{s}:$ & $\begin{array}{l}\text { Angle of incidence between the rays of yhe } \\
\text { sun and the normal to the surface }\left[{ }^{\circ}\right]\end{array}$ \\
\hline$\Phi(\lambda):$ & $\begin{array}{l}\text { Incident spectral photon flux density } \\
{\left[\mathrm{m}^{-2} \cdot \mathrm{nm}^{-1} \cdot \mathrm{s}^{-1}\right]}\end{array}$ \\
\hline$\omega:$ & True solar time $\left[{ }^{\circ}\right]$ \\
\hline
\end{tabular}

\section{Acknowledgments}

The authors would like to thank B. García-Domingo, F. Chenlo, J. Aguilera, M. Fuentes, and J. V. Muñoz for their help. This work was supported by the Spanish Ministry of Education, Social Policy and Sports, within the frame of the Project under expedient code ENE200908302, the Spanish Science and Innovation Ministry and the ERDF within the frame of the Project under expedient code ENE2008-05098/ALT, and the Andalusian Research Plan within the Project under expedient code TEP- 5045M. One of the authors (M. Torres-Ramírez) greatly acknowledges Fundación Iberdrola for granting an "Energy for Research" Scholarship.

\section{References}

[1] A. Jäger-Waldau, "Research, solar cell production and market implementation of photovoltaics," PV Status Report, European Commission, DG Joint Research Centre, Ispra, Italy, 2011.

[2] A. Jäger-Waldau, "Thin film photovoltaics: markets and industry," International Journal of Photoenergy, vol. 2012, Article ID 768368, 6 pages, 2012.

[3] Fraunhofer Institute for Solar Energy Systems, "ISE photovoltaics report," Tech. Rep., 2013, http://www.ise.fraunhofer .de/en.

[4] G. L. Araujo and E. Sánchez, "Analytical expressions for the determination of the maximum power point and the fill factor of a solar cell," Solar Cells, vol. 5, no. 4, pp. 377-386, 1982.

[5] G. L. Araujo, E. Sánchez, and M. Martí, "Determination of the two-exponential solar cell equation parameters from empirical data," Solar Cells, vol. 5, no. 2, pp. 199-204, 1982.

[6] C. R. Osterwald, "Translation of device performance measurements to reference conditions," Solar Cells, vol. 18, no. 3-4, pp. 269-279, 1986.

[7] B. Kroposki, K. Emery, D. Myers, and L. Mrig, "A comparison of PV module performance evaluation methodologies for energy ratings," in Proceedings of the 1st World Conference on Photovoltaic Solar Energy Conversion, pp. 858-862, Waikoloa, Hawaii, USA, December 1994.

[8] B. Marion, "A method for modeling the current-voltage curve of a PV module for outdoor conditions," Progress in Photovoltaics, vol. 10, no. 3, pp. 205-214, 2002.

[9] B. Marion, S. Rummel, and A. Anderberg, "Current-voltage curve translation by bilinear interpolation," Progress in Photovoltaics, vol. 12, no. 8, pp. 593-607, 2004.

[10] M. Fuentes, G. Nofuentes, J. Aguilera, D. L. Talavera, and M. Castro, "Application and validation of algebraic methods to predict the behaviour of crystalline silicon PV modules in Mediterranean climates," Solar Energy, vol. 81, no. 11, pp. 1396$1408,2007$.

[11] W. Zhou, H. Yang, and Z. Fang, "A novel model for photovoltaic array performance prediction," Applied Energy, vol. 84, no. 12, pp. 1187-1198, 2007.

[12] F. Almonacid, C. Rus, L. Hontoria, M. Fuentes, and G. Nofuentes, "Characterisation of Si-crystalline PV modules by artificial neural networks," Renewable Energy, vol. 34, no. 4, pp. 941-949, 2009.

[13] A. Virtuani, H. Müllejans, and E. D. Dunlop, "Comparison of indoor and outdoor performance measurements of recent commercially available solar modules," Progress in Photovoltaics, vol. 19, no. 1, pp. 11-20, 2011.

[14] C. Cornaro and A. Andreotti, "Influence of Average Photon Energy index on solar irradiance characteristics and outdoor 
performance of photovoltaic modules," Progress in Photovoltaics, vol. 21, no. 2, pp. 996-1003, 2013.

[15] N. Martín and J. M. Ruiz, "A new method for the spectral characterization of PV modules," Progress in Photovoltaics, vol. 7, no. 4, pp. 299-310, 1999.

[16] K. H. Lam, J. Close, and W. Durisch, "Modelling and degradation study on a copper indium diselenide module," Solar Energy, vol. 77, no. 1, pp. 121-127, 2004.

[17] W. Durisch, B. Bitnar, J.-C. Mayor, H. Kiess, K.-H. Lam, and J. Close, "Efficiency model for photovoltaic modules and demonstration of its application to energy yield estimation," Solar Energy Materials and Solar Cells, vol. 91, no. 1, pp. 79-84, 2007.

[18] T. Minemoto, S. Nagae, and H. Takakura, "Impact of spectral irradiance distribution and temperature on the outdoor performance of amorphous Si photovoltaic modules," Solar Energy Materials and Solar Cells, vol. 91, no. 10, pp. 919-923, 2007.

[19] T. Minemoto, M. Toda, S. Nagae et al., "Effect of spectral irradiance distribution on the outdoor performance of amorphous $\mathrm{Si} /$ thin-film crystalline Si stacked photovoltaic modules," Solar Energy Materials and Solar Cells, vol. 91, no. 2-3, pp. 120-122, 2007.

[20] N. Katsumata, Y. Nakada, T. Minemoto, and H. Takakura, "Estimation of irradiance and outdoor performance of photovoltaic modules by meteorological data," Solar Energy Materials and Solar Cells, vol. 95, no. 1, pp. 199-202, 2011.

[21] T. Minemoto, S. Fukushige, and H. Takakura, "Difference in the outdoor performance of bulk and thin-film silicon-based photovoltaic modules," Solar Energy Materials and Solar Cells, vol. 93, no. 6-7, pp. 1062-1065, 2009.

[22] S. R. Williams, T. R. Betts, T. Helf, R. Gottschalg, H. G. Beyer, and D. G. Infield, "Modelling long-term module performance based on realistic reporting conditions with consideration to spectral effects," in Proceddings of the 3rd World Conference on Photovoltaic Energy Conversion, pp. 1908-1911, Osaka, Japan, May 2003.

[23] T. Minemoto, Y. Nakada, H. Takahashi, and H. Takakura, "Uniqueness verification of solar spectrum index of average photon energy for evaluating outdoor performance of photovoltaic modules," Solar Energy, vol. 83, no. 8, pp. 1294-1299, 2009.

[24] J. Tsutsui and K. Kurokawa, "Investigation to estimate the short circuit current by applying the solar spectrum," Progress in Photovoltaics, vol. 16, no. 3, pp. 205-211, 2008.

[25] T. Ishii, K. Otani, T. Takashima, and Y. Xue, "Solar spectral influence on the performance of photovoltaic (PV) modules under fine weather and cloudy weather conditions," Progress in Photovoltaics, vol. 21, no. 4, pp. 481-489, 2013.

[26] G. Nofuentes, M. Alonso-Abella, J. V. Muñoz et al., "Influence of spectral irradiance distribution and module temperature on the outdoor performance of some thin film PV module technologies," in Proceedings of the 26th European Photovoltaic Solar Energy Conference, Hamburg, Germany, September 2011.

[27] G. Nofuentes, B. García-Domingo, M. Fuentes et al., "Comparative analysis of the effects of spectrum and module temperature on the performance of thin film modules on different sites," in Proceedings of the 26th European Photovoltaic Solar Energy Conference, Frankfurt, Germany, September 2012.

[28] H. Wilk, "Electricity yield of PV systems in different climates and dependence of module efficiency as a function of irradiance and other factors," in Proceedings of the 14th European PV Solar Energy Conference, Barcelona, Spain, July 1997.
[29] A. Luque and S. Hegedus, Handbook of PV Science and Engineering, John Wiley \& Sons, Chichester, UK, 2003.

[30] G. Nofuentes, M. Fuentes, J. Aguilera, and J. V. Muñoz, "An assessment on simple modeling approaches to the electric behavior of two cis pv modules in a sunny climate," Journal of Solar Energy Engineering, Transactions of the ASME, vol. 131, no. 3, Article ID 031013, 10 pages, 2009.

[31] Y. Nakada, S. Fukushige, T. Minemoto, and H. Takakura, "Seasonal variation analysis of the outdoor performance of amorphous Si photovoltaic modules using the contour map," Solar Energy Materials and Solar Cells, vol. 93, no. 3, pp. 334337, 2009.

[32] T. Minemoto, H. Takahashi, Y. Nakada, and H. Takakura, "Outdoor performance evaluation of photovoltaic modules using contour plots," Current Applied Physics, vol. 10, no. 2, pp. S257-S260, 2010.

[33] T. Ishii, K. Otani, and T. Takashima, "Effects of solar spectrum and module temperature on outdoor performance of photovoltaic modules in round-robin measurements in Japan," Progress in Photovoltaics, vol. 19, no. 2, pp. 141-148, 2011.

[34] S. Nann and C. Riordan, "Solar spectral irradiance under overcast skies," in Proceedings of the 21st IEEE Photovoltaic Specialist Conference, pp. 1110-1115, Orlando, Fla, USA, May 1990.

[35] F. Fabero and F. Chenlo, "Variance in the solar spectrum with the position of the receiver surface during the day for PV applications," in Proceedings of the 22nd IEEE Photovoltaic Specialist Conference, pp. 812-817, Las Vegas, Nev, USA, October 1991.

[36] A. Luque and S. Hegedus, Handbook of PV Science and Engineering, John Wiley \& Sons, Chichester, UK, 2nd edition, 2011.

[37] Standard ASHRAE 93-77, Methods of Testing to Determine the Thermal Performance of Solar Collectors, American Society of Heating, Refrigeration, and Air Conditioning Engineers, New York, NY, USA, 1977.

[38] S. Nann and K. Emery, "Spectral effects on PV-device rating," Solar Energy Materials and Solar Cells, vol. 27, no. 3, pp. 189216, 1992.

[39] E. E. Van Dyk, A. R. Gxasheka, and E. L. Meyer, "Monitoring current-voltage characteristics and energy output of silicon photovoltaic modules," Renewable Energy, vol. 30, no. 3, pp. 399-411, 2005.

[40] A. J. Carr and T. L. Pryor, "A comparison of the performance of different PV module types in temperate climates," Solar Energy, vol. 76, no. 1-3, pp. 285-294, 2004.

[41] E. E. van Dyk and E. L. Meyer, "Analysis of the effect of parasitic resistances on the performance of photovoltaic modules," Renewable Energy, vol. 29, no. 3, pp. 333-344, 2004. 

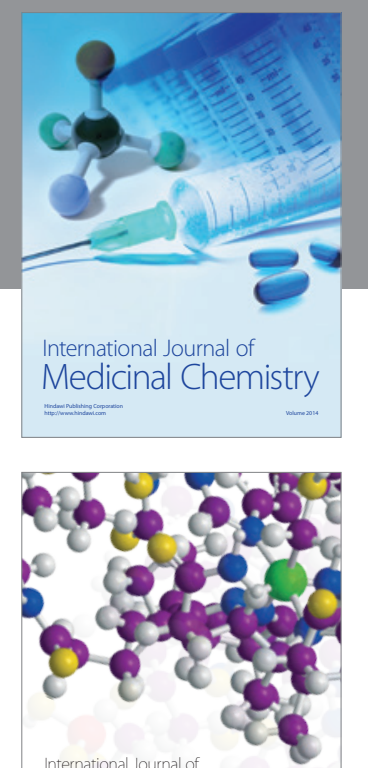

\section{Carbohydrate} Chemistry

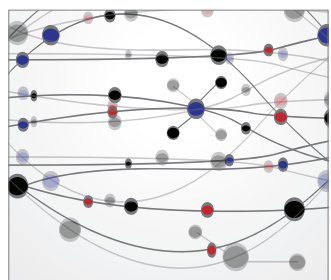

The Scientific World Journal
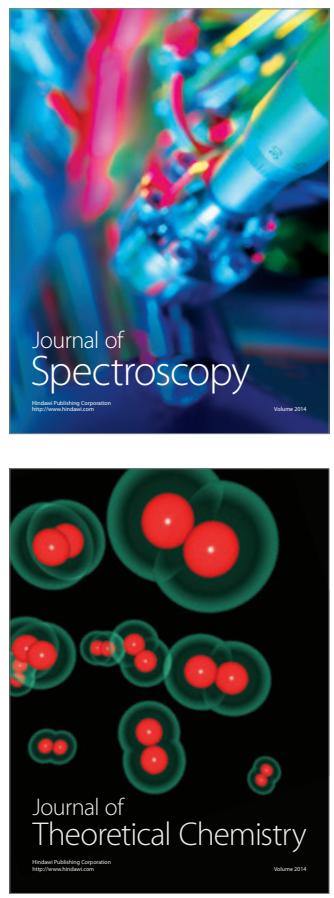
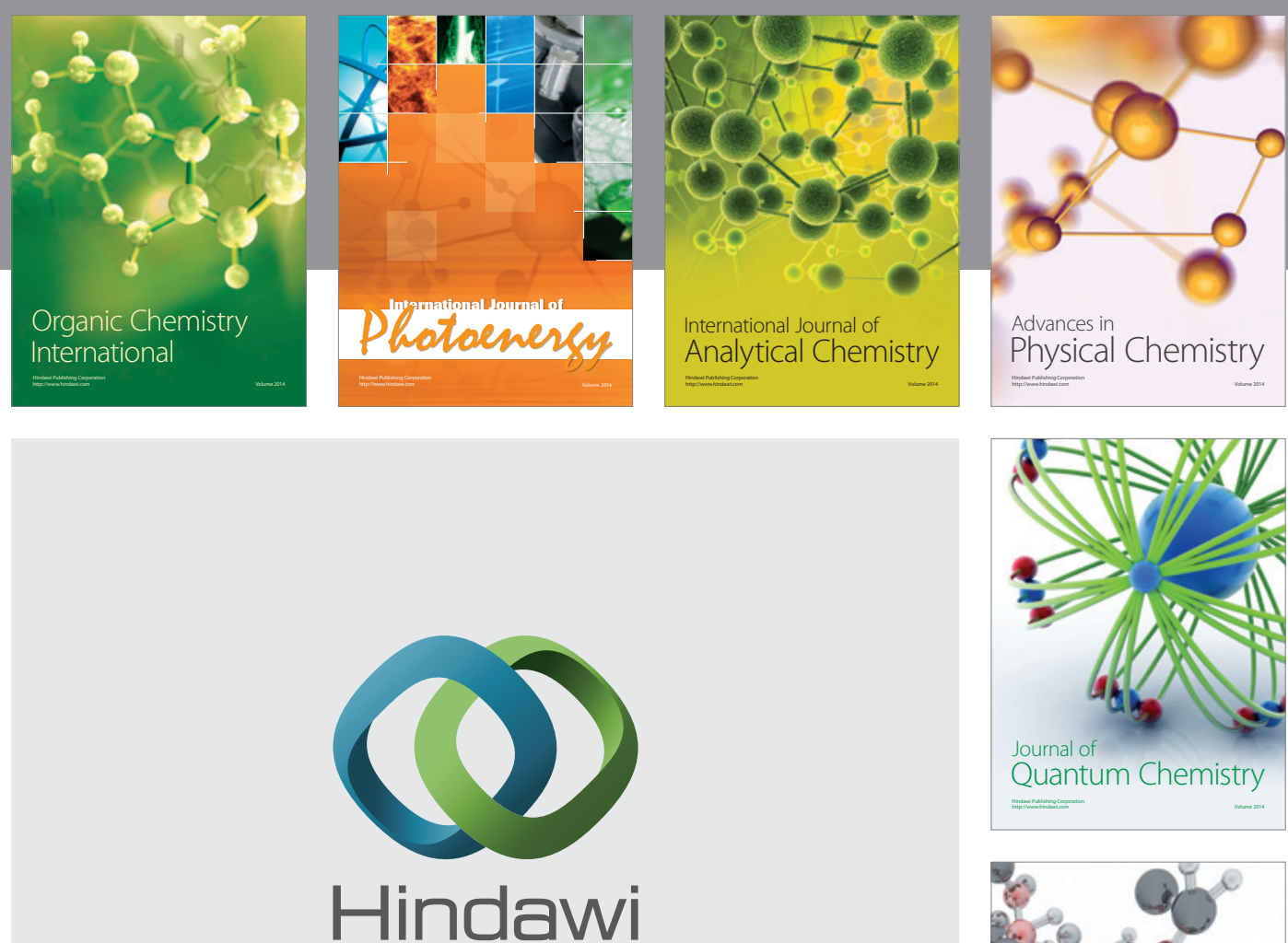

Submit your manuscripts at

http://www.hindawi.com

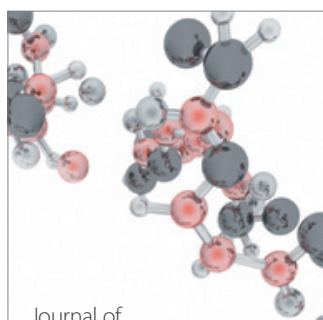

Analytical Methods

in Chemistry

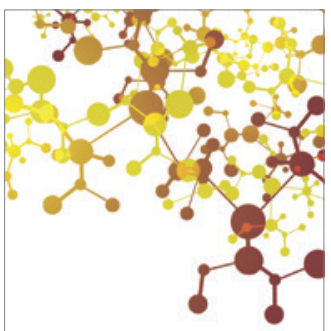

Journal of

Applied Chemistry

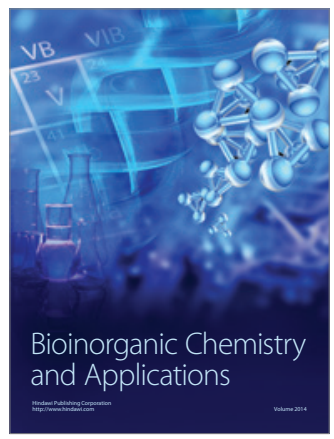

Inorganic Chemistry
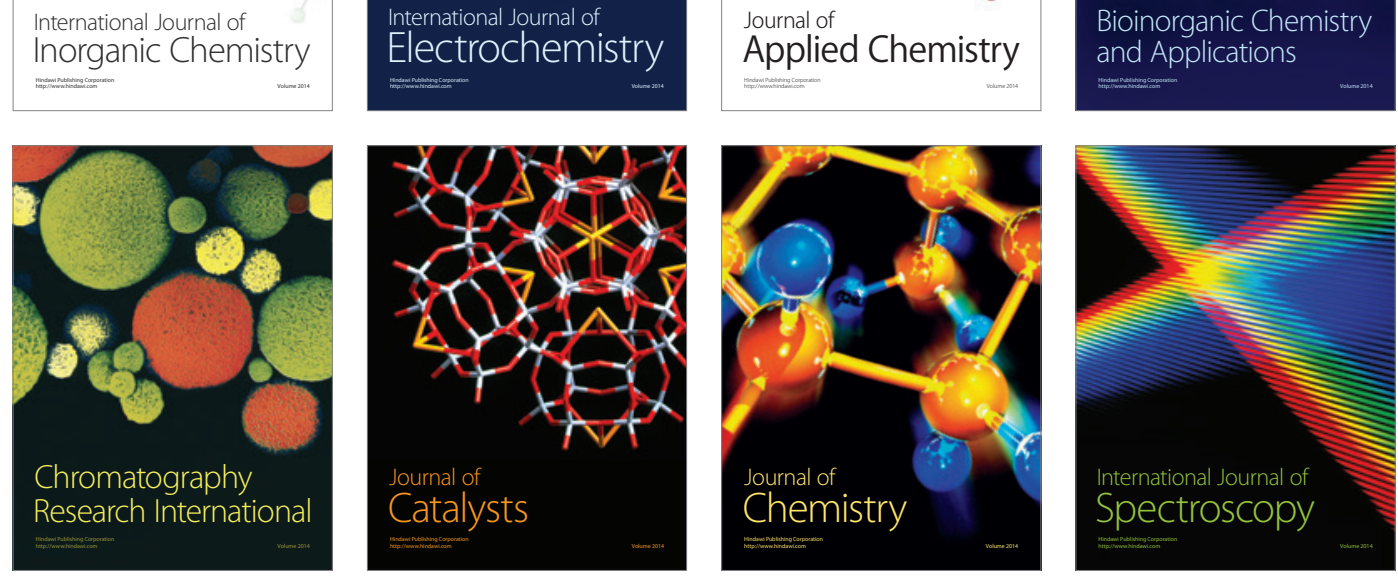